\title{
С.М. Пястолов
}

\section{«КАЧЕЛИ» УПРАВЛЕНИЯ В МНОГОУРОВНЕВОЙ РЕАЛЬНОСТИ НАУКИ}

\author{
DOI: $10.31249 / \mathrm{scis} / 2019.00 .09$
}

Аннотация. В ситуациях неопределенности естественное решение администратора - предложить организации квазивербализованную институциональную форму. Метафора разумного организма в этом случае предостерегает от управляющих мер, предпринимаемых под воздействием краткосрочных интересов. Известные теоретические описания методов управления (i) «снизу вверх» и (ii) «сверху вниз», в авторской концепции эволюционного (спирального) развития институциональных форм, дополнены метафорой «качелей», когда в рамках схемы спирального развития наблюдается движение (а) по часовой стрелке: от культуры (способа) мышления - к рутинам, институтам; и (б) против часовой стрелки: от институтов - к рутинам и организационной культуре (способам) мышления. Порядок организационных форм структурирован целями.

Abstract. In situations of uncertainty the most natural decision of an administrator is to offer the organisation a quasiverbalised institutional form. In this case a metaphor of a smart organism warns against the operating measures undertaken under the influence of short-term interests. Theoretical descriptions of strategic regulation methods: (i) «upstream» and (ii) «downstream», within the framework of the Helical Institutional Development Scheme (HIDS) are supplemented by a metaphor of «swing». Thus one can interpret those methods within the limits of the spiral development movement as (a) clockwise: from culture (means) of thinking - to routines; and (b) counter-clockwise: from institutes - to routines and organizational culture (means) of 
thinking. The author stresses that the order of organizational forms is structured by the mission.

Ключевые слова: бюрократизация науки; фундаментальные исследования; многоуровневая реальность; метод существенной метафоры; развитие институциональных форм.

Keywords: bureaucratization of science; basic research; multilevel reality; essential metaphor method; development of institutional forms.

The scientific research enterprise is a cornerstone of modern society. National Academies of Sciences, Engineering, and Medicine ${ }^{1}$.

Он управлял теченьем мыслей И только потому - страной.

Б. Пастернак

Исследования «экономики знаний», сопровождаемые появлением новых научных дисциплин («Исследования науки и технологий» (Science and Technology Studies), «Наука о науке» (Science of Sciences), «Технонаука» (Technoscience) и др.), приводят, помимо прочего, к пониманию того, что развитие науки должно быть обеспечено не только производством нового знания, но также «памятью», как обеспечивается деятельность всякого разумного организма.

Особенностью текущего периода является также то, что наука выводится «на суд общественности» (см., например: [1]); п. 5 в списке целей проекта НАСА «Открытое программное обеспечение»: «Максимизировать общественную полезность NASA» ${ }^{2}$. Общественность обеспокоена в том числе возможными непредсказуемыми последствиями проникновения информационных тех-

${ }^{1}$ «Научное предприятие является краеугольным камнем современного общества» [15].

${ }^{2}$ Семь целей политики Открытого ПО (OSS), разработанных Комитетом Национальных академий США: «1. Содействовать инновациям и открытиям. 2. Увеличить прозрачность, доступность и повторное использование разработок OSS, финансируемых НАСА. 3. Содействовать научному воспроизводству. 4. Поощрять сотрудничество внутри и за пределами НАСА. 5. Максимизировать общественную полезность NASA. 6. Уважать безопасность и неприкосновенность частной жизни граждан. 7. Поддерживать более широкую государственную политику» $[16$, с. $1-2]$. 
нологий во все сферы общественной жизни. Действительно, появляются новые зависимости от технологий, что усугубляет риски кибервойн, формирует новые угрозы в области технологической и иных видов безопасности.

В таких условиях организации научной сферы должны каким-то образом легитимизировать расходы на свою деятельность, право распоряжаться соответствующими активами, предоставленными обществом. Связанные с решением этой задачи технические проблемы призваны решать бюрократические структуры. При этом возникают определенные неудобства и негативные эффекты чрезмерной бюрократизации. Рассматриваемый феномен довольно сложен. Здесь приходится иметь дело с наложением нескольких механизмов координации взаимодействий агентов научной сферы (АНС), систем ценностей, свойственной различным типам миров-соглашений. В публикациях по теме бюрократии можно встретить различные виды ее классификации. Так, выделяют административную бюрократизацию, от которой больше «страдают» научные работники университетов; академическую бюрократизацию, уровень которой относительно более высок в общественных (государственных) исследовательских организациях.

В последнем случае бюрократизация может быть измерена и оценена при помощи таких очевидно определяемых величин, как среднее время, необходимое для оформления срочного контракта; время, необходимое для организации встреч, семинаров, конференций и др. мероприятий; на участие в мероприятиях и на оформление документации по грантам/проектам; на презентации результатов проектов, заключение договоров о сотрудничестве перед началом проекта; на утверждение (изменение) проектных бюджетов; на обоснование и оформление командировок; на приобретение научных материалов: книг, журналов, компьютеров, программного обеспечения, оборудования и т.п.; число документов, заполняемых в исследовательской организации.

К факторам бюрократизации, описанным в теории, относятся: отрицательный эффект масштаба (растущая сложность требует увеличения административных расходов); необходимость госрегулирования при развитии международных контактов (необходимо привести рутины в соответствие внешним требованиям). Кроме того, рост административного аппарата может иметь и внутренние причины (администраторы, стремясь оправдать рост расходов, а также адаптируясь к внешнему регулированию, поддерживают внедрение новых рутин и процедур). 
В качестве целевой функции в большинстве такого рода исследований выбирается величина среднего научного продукта, измеренная как число внутренних и внешних публикаций. Такая же целевая функция принята и разработчиками Национального проекта «Наука» в Российской Федерации. Параметрами этой функции для оценки уровня бюрократизации могут быть: время, потраченное на ту или иную административную деятельность; количество заполненных документов. Многие исследования, проведенные в различных странах, подтверждают правдоподобность гипотезы о том, что бюрократизация не способствует росту научных достижений.

В данной статье мы выделим и исследуем наиболее общие признаки феномена бюрократии и покажем, в каких случаях непрофессиональное обращение со столь деликатным инструментом может привести к опасному «раскачиванию корабля» науки.

В связи с понятием многоуровневой реальности науки следует особо выделить один из приоритетов Стратегии научно-технического развития. Он же выбран и в качестве названия одного из семи советов, сформированных в рамках национального проекта «Наука» (руководитель: А.А. Дынкин). Данное направление некоторые эксперты даже называют «загадочным». Такое высказывание обнаружено на портале «Индикатор» / indicator.ru.

Под руководством академика Дынкина по названному направлению работают шесть групп (протокол от 16.07.2018). Темы исследований групп: 1. Анализ «институциональных ограничений инновационной экономики». 2. Феномены демографического перехода и 4-й промышленной революции. 3. Парирование экологических проблем. 4. Внешние военные и невоенные угрозы национальной безопасности. 5. Этнополитические, трансграничные и вооруженные конфликты. 6. Социальная и культурная безопасность.

Запущены программы Президиума РАН. Однако в проекте министерства вы не найдете упоминания о фундаментальных исследованиях. Посредством семантических интервенций администраторы Европейской комиссии (ЕК) заблаговременно «упразднили» эту категорию, снивелировав различия между фундаментальной и прикладной наукой (в начале 2000-х). А также, ранее, заменив категорию научно-технического комплекса концепцией Национальной инновационной системы. Посредством внедрения категорий «глобальные вызовы», «приоритеты» и др. метод научного плани- 
рования был заменен спортивным азартом. Российские чиновники следуют за ЕК с лагом примерно в 10 лет.

Общим качеством администраторов науки по обе стороны Атлантического океана является то, что их планы и действия проектируются и реализуются в основном в пространствах-уровнях так называемого гибрида рыночного и технологического соглашений. Все более сжимаются уровни гражданского, экологического и соглашения творческой деятельности. Видимо, поэтому и возникает у некоторых экспертов ощущение «загадочности», когда речь заходит о гуманитарном аспекте научно-технологического развития.

Г.В. Трубников, один из «молодых и перспективных» руководителей, на которых рассчитывает Министерство науки и высшего образования, в одном из своих интервью порталу pravda.ru замечает: «...в целом ведь для ученого, исследователя основной продукт его деятельности - это публикации в журналах, входящих в международные рейтинги, т.е. наиболее читаемых. А разве есть возможность оценивать результаты иначе?» ${ }^{1}$ Заметим, что такие возможности широко обсуждаются в профессиональных сообществах. См., например: [7]. Если же применять только формальные показатели и денежное стимулирование, то получится так, как вышло с показателями публикационной активности пятерки лучших российских университетов (ТОП 5-100). Портал «Индикатор» наглядно показывает, что после получения господдержки в 2013-м был отмечен сравнительно небольшой, хотя и заметный рост данной целевой функции. Однако продержался он не долее трех лет.

Видимо поэтому, новое руководство министерства решило переключить фокус внимания на научные организации и предприятия. Замминистра Г.В. Трубников в том же интервью в этой связи использует наглядный образ: «корабль науки немножко качнуло».

К вопросу о «качке». Так бывает. Но если в условиях нестабильности капитан будет управлять своим кораблем только по формальным показателям, то возможны самые неприятные последствия. Методика наглядно-образного моделирования может предложить образ перевернувшегося корабля. Трагедию лайнера Costa Concordia продолжают изучать эксперты и удивляются: все же делалось по инструкции! [12]. Giustiniano и др. используют для описания ситуации новый термин, возникший в теории

\footnotetext{
${ }^{1}$ Режим доступа: https://www.pravda.ru/science/1403902-trubnikov/
} 
управления, - Zemblanity. Он имеет значение, противоположное Serendepity (когда все - превосходно). На русский переводится плохо, но, думаю, каждый найдет подходящие эпитеты, если что случится; не дай Бог!

На корейском пароме Sevol звучали четкие команды: «Не покидать каюты. За вами придут». Те русские школьники, которые спаслись, решили не слушать команд, а выбираться самостоятельно. Круговая порука и взаимовыручка помогла группе русскоговорящих туристов в Таиланде в 2004-м. По призыву «Кто говорит по-русски - сюда!» люди забрались на крышу отеля, встали в круг, обнялись и удержались под напором воды.

Такого рода наблюдения, поддержанные теоретическими выкладками, позволяют сформулировать важное требование к условиям безопасности в социотехнических системах: необходимо нарабатывать навыки взаимовыручки и доверие друг другу и всей системе отношений. То есть отрабатывать реакции разумного общественного организма.

Но каким образом такая система строится и как измерить доверие?

Очевидно, иерархическое гомогенное академическое сообщество, сгруппированное вокруг элитных университетов и кафедр, является лишь одним из уходящих способов организации пространств научной деятельности. Действительно, характеристикой академического мира в последние десятилетия, помимо его стремительного развития, является растущее разнообразие организационных форм и процессов [9, с. 218]. Здесь Г.В. Трубников представляет зрелое экспертное суждение: необходимо понимать общее направление и иметь свободу маневра. Именно об этом писал В. Буш в своем докладе президенту США 1945 г. «Наука бесконечный передний край» («Science - The Endless Frontier», 1945 [17]).

Обращаясь к истории термина (англ.: frontier research), заметим, что понятие «передний край науки» (альтернативный перевод: «пограничное исследование») было предложено европейским администраторам науки советниками из-за океана, по мнению Флинка и Калдевай, потому что «передний край» / «граница» было новым понятием для академической Европы. «Фронт», «передний край» в Америках XIX в. являлись управляющими объектами соглашений о методах и способах исследования и эксплуатации осваиваемых территорий. «Особый американский характер», описанный в хрониках, «отмечен жестоким индивидуализмом, праг- 
матизмом и эгалитаризмом» и «сильно отличается от европейского созерцательного характера» [10, с. 15]. Руководство США хорошо понимало, что глобальное доминирование страны основывается на технологическом превосходстве, и стало предпринимать соответствующие меры. Так, в составе ВВС США была создана RAND Corporation, в которой работали многие впоследствии ставшие широко известными исследователи.

Данное и другие семантические интервенции, по мнению экспертов, способствовали разрушению того общественного договора, который существовал в рамках так называемой «линейной модели инноваций». С 1950-х линейная модель выражала идею о том, что инновации могут быть реализованы путем определенных последовательностей действий. (Именно такая определенность, так или иначе, гарантировала «защищенность пространства» для ученых.) Хотя тезис о сложности инновационных процессов не был опровергнут, линейная модель до сих пор присутствует в политических дискурсах, но скорее как идея, чем как модель в техническом и экономическом смыслах.

Эксперименты с терминами («семантические новшества») раскрывают свое значение в контексте информационной войны. Помимо «бесконечного фронта» В. Буша, в 1968-м был опубликован «Американский вызов» Сервэн-Шрайбера («The American Challenge»). И далее набор инструментов, называемых специалистами «семантическими», расширяется. К нему прибавляются понятия «пространство исследований», национальная инновационная система, категория «ответственных исследований и инноваций», «великие вызовы». Как показывает пример инновационной политики США, востребованность этих инструментов растет. Новую терминологию используют, в частности, Национальный стратегический план «Нанотехнологическая инициатива» (ННИ), проект «Нанотехнологии в социальных сетях» Национального научного фонда США [11, с. 62]. Сегодня эти структуры управляют годовым бюджетом проекта в объеме 1,5 трлн долл. США [14, с. 1]. Данные расходы общественных средств, очевидно, требуют легитимизации. Причем вердикт должен быть вынесен «судом общественности». «Демократия» на поле научных исследований фактически вытесняет меритократию. Параллельно с этим, подспудно, происходит вытеснение из практики науки фундаментального исследования (basic research - понятие стало активно использоваться после доклада В. Буша). 
Такая замена не может происходить быстро и явно: довольно много заинтересованных лиц с той и с другой стороны, обладающих значимой переговорной силой (рыночной властью). За эту власть ведут борьбу «академические профессиональные группы» (АПГ) - понятие, введенное Хиршманом [13]. Во многом благодаря их усилиям возводятся эпистемологические барьеры на границах дисциплин (не только и не столько в целях защиты от назойливых профанов). Пространство науки сегодня разделено на тысячи полей (доменов). В электронных источниках их можно насчитать более 8000 .

Ключевые факторы стратегий ученых, по мере роста их вовлеченности в процессы бюрократизации, можно классифицировать следующим образом: (1) идея «чистой науки», (2) гибрид: «чистая наука» ПЛЮС научно-административный интерес, (3) «наука = политика».

В этой связи заметим, что анализ информационных событий в сфере науки и технологий подтверждает особенности институциональной динамики, известные специалистам. Среди прочего: прежде чем произойдет трансформация институциональных форм в научной сфере, происходит «эпистемологический захват» пространства той научной дисциплины, которая должна обосновать соответствующие институциональные изменения. То есть создать соответствующие убеждения и представления в сознании участников процессов и затем - паттерны поведения.

В большинстве текстов, затрагивающих проблемы бюрократизации, данный феномен соотносится с неким, не вполне определенным общественным институтом [4], роль которого двойственна: его влияние на развитие управляемой подсистемы общества может быть положительным и отрицательным. В простой версии оценки сравниваются расходы на содержание управленческого аппарата с аналогичными показателями предшествующих периодов и при этом данные показатели соотносятся с общим «выпуском» и / или затратами на производящий персонал организации. Так, М. Кочиа в 2009 г. указала, что в калифорнийских университетах соотношение расходов на обучение и на администрирование в период 1967-1992 гг. изменилось от 6:1 до 3:1, а административный персонал увеличился на $151 \%$, тогда как ППС - на 61\%. Аналогичные наблюдения были получены для других стран, а для Италии организован кейс-стади [8]. С. Егерев в работе 2018 г. отметил, что «административный финансовый навес» над исследовательскими проектами вырос за прошедшие 10 лет в 2 раза [3, с. 154]. 
Авторская концепция, объясняющая феномен бюрократизации, основана на предпосылках конвенциальной версии французского институционализма. В предшествующих работах эти предпосылки были дополнены условиями: наличия фреймов рациональности; наличия уровней рациональности. Как следствие, получен вывод о дискретности благ, что, в свою очередь, соотносится с условием дискретности поведения веберовского типа.

В целях построения модели взаимовлияния институциональных структур и экономических стратегий агентов научной сферы (АНС) приняты следующие предположения: (1) блага определенного уровня должны быть соотнесены с тем количеством затрат энергоинформации, которое необходимо для их получения и потребления; (2) существует зависимость между способностями принимать разумные решения и объемом доступной индивиду информации. Решения выражаются в поведении, которое, в свою очередь, разделено на типы: целерациональное, целостнорациональное, традиционное, аффективное; (3) поведение индивида обусловлено его интеллектуальными способностями, а также правилами, нормами, рутинами организации, его собственными убеждениями и представлениями, традициями и привычками, эмоциями, психологическими доминантами и инстинктами.

Полученная в результате обобщения изложенных концепций и на основании принятых предположений схема спирального развития институциональных структур (HIDS - Helical Institutional Development Scheme) характеризуется следующими свойствами элементов ${ }^{1}$ :

i. Движение от одной группы элементов к другой в формате $H I D S$ осуществляется только по ходу часовой стрелки. Таким образом, например, представления индивида (психические формы) не могут сформироваться под влиянием права силь, неформальных или формальных сочиальных правил и даже логики (общественных форм). Однако представления могут появиться, как результат опьта под воздействием стимулов в виде возможности получить соответствующие блага (или антиблага), а также могут быть унаследованы от родителей или общества (как результат воспитания и / или обучения).

Следовательно, при формировании нового знания (укореняющегося затем в институтах) действует механизм координации

${ }^{1}$ Рисунки, наглядно представляющие рассматриваемую схему, можно найти в открытых публикациях автора, например в [6]. 
ex post, так как соответствующие качества человеческого капитала ещче не сформированы.

Один из аспектов этого свойства известен в институциональной теории в следующей формулировке: любой институт можно рассматривать и как средство, и как следствие формирования ожиданий и представлений; формируя ожидания и представления, институт обретает устойчивость.

ii. При переходе от одного этапа к другому в прочессе формирования психических и общественных форм могут последовательно взаимодействовать элементы только двух соседних групп. Так, например, наличие какого-либо из возможных благ (наличие информации о возможности получения блага) не может само по себе вызвать появление действенных общественных институтов, минуя фазу формирования соответствующих индивидуальных представлений (убеждений) у конкретных субъектов и, затем, у групп людей. Здесь, с точки зрения $H I D S$, представления индивида предшествуют (по ходу спирали) общественным институтам. А если двигаться от институтов к психическим формам, то между этими объектами расположен сектор благ. Практика (в т.ч. российских реформ) показывает, что если импортированные институты не генерируют нужные обществу блага (или общество не воспринимает блага так, как это задумал планировщик), то институты «не приживаются».

Следовательно, только в сообществах с установившимися институтами может осуществляться координаџия действий субъектов на основе общих ожиданий и убеждений (механизм координации ex ante).

Обнаружено также парадоксальное свойство, проявляющее себя в логике развития сообществ, основанных на знании.

iii. Чем выше уровень организованности сообщества, тем меньше его способность к изменениям, выражающаяся в способности накапливать и распространять неявное знание.

Уровень организованности непосредственно связан с уровнем бюрократизации. В статье 2003 г., сопровождавшей перевод статьи П. Дэвида и Д. Форэ [2; 5], говорилось о том, что неявное знание непосредственно принадлежит «знающим». С их уходом или «забыванием», ввиду невостребованности, знание теряется. Формализованные тексты, нормативы, то, что может хранить и передавать бюрократия, составляют лишь часть всего «пространства знания» в организации. 
iv. сочиальные паттерны поведения могут быть сформировань только при наличии соответствующих индивидуальных представлений и убеждений; последние, в свою очередь, должны сформироваться в результате обучаюших действий.

Из названных выше свойств HIDS можно заключить, что процесс адаптации стратегий АНС к меняющимся внешним условиям будет эффективным (причем эффективность усиливается за счет синергетических эффектов), если создаваемые образы будут находить свое воплощение в общественных формах (вещах) и предметах реального мира.

Выявленные свойства позволили сформулировать научное объяснение феномена бюрократизации науки и, в частности, уверенность администраторов в эффективности такого вида новаций, когда в качестве целевой функции выбирается формализованный параметр. Действительно, радикальные социально-экономические меры могут оказаться действенными в краткосрочном периоде, даже если они противоречат доминирующему организационному укладу, но соответствуют по своим формам рутинам бюрократической машины управления. В этом случае большая часть трансакций локализуется в пространстве одного из соглашений, а в других «мирах» формируются компенсаторные механизмы, нейтрализующие воздействие новации.

В ряду организационных моделей в данном рассмотрении нас интересует профессиональная бюрократия. Это форма организации, которая формируется в результате взаимовлияния организационных паттернов и свободного рынка профессий. Образование и обучение в этой модели характеризуется узкой специализацией, ориентацией на элитарное, формализованное знание. Система, созданная вокруг такой организации, поощряет генерацию артикулированного знания, индивидуальные успехи в образовании, призванные обеспечить карьерный рост.

Выходя на уровень общества, такая система не способствует формированию стимулов для накопления и распространения знания, особенно «молчаливого» (неявного). Когда же делаются попытки построить инновационную систему на основе принципов профессиональной бюрократии, то без опоры на потенциал неявного знания (культура, традиции, укорененные представления) подобная система оказывается маложизнеспособной. Однако бюрократия профессионалов доминирует в тех экономических системах, где в управлении сильна англосаксонская традиция. В этом случае преобладает узкоспециализированный подход в процессах 
генерации и передачи знаний. Более распространено знание артикулированное, а инновации на своем пути встречают серьезные препятствия.

Как показывает практика, недостатки профессиональной бюрократической модели преодолеваются в том числе путем создания гибридов соглашений (преимущественно этот гибрид включает - рыночное, технологическое и соглашение творческой деятельности). А процессы создания гибридов обеспечиваются, помимо прочего, импортом носителей культуры творчества и технологического мышления (в так называемых развитых странах в этой роли часто выступают выходцы из стран бывшего соцлагеря, Индии, Китая и др.).

«Бюрократия машины» является, по сути, версией модели профессиональной бюрократии. Это может иметь место в том случае, когда цели организации длительное время оказываются фиксированными. Весьма вероятно такое развитие событий, когда организация утрачивает представление о своих целях, но в то же время пытается сохранить организационные рутины и внешние формы. Собственно, в том числе и ради преодоления последствий разного рода негативных эффектов, возникающих в рамках линейной модели, были предложены такие организационные структуры, как национальные научные фонды, агентства, центры превосходства и другие модификации грантовой системы.

Сетевые организации, построенные по типу инновационных сообществ (сообществ профессионалов), относятся к классу «операционной адхократии». Это способствует формированию сетей социальных коммуникаций и распространению знания. Важным достоинством сети являются большие возможности трансфера знаний. Так, взаимопроникновение «обучающихся» и «трудящихся» сообществ стало в этом случае характерной особенностью системы обучения. Характеризует такую инновационную систему $^{1}$ невысокая склонность к стандартизации методов исследований, большие возможности для создания и распространения неявного знания. Для описания подобных явлений потребовались такие понятия, как «информационные сигналы», «перелив знаний», «трансфер через и поверх» границ: географических и дисциплинарных.

${ }^{1}$ Здесь определение «инновационной системы» соответствует также определению системы научных исследований и разработок, в целом - научнотехнической сферы. 
Можно также отметить особое направление администрирования в научной (и не только) сфере, поддерживаемое методикой, обозначаемой термином «играизация» (gamification). Соответствующая область научных исследований за последние несколько лет активно развивается и ее рост не показывает признаков замедления [18].

В теоретических исследованиях названный тренд проявил себя в форме «экспериментальной экономики». Согласимся с тем, что эксперимент - это, во многом, игра (в методологическом смысле - игра с Природой). А в современной же «хрематистике» дух игры присутствует имманентно. Вспомним ее сравнение с игорным домом Дж.М. Кейнса. А современные авторы в своих курсах по геймификации утверждают, что эффективность бизнеса будет гораздо выше, если работа станет в большей степени игрой с системой вознаграждений, а не обязанностью. Кроме того, игровые методы получили широкое распространение в системах управления. Теория, нацеленная на достижение определенных целей в сложных социально-экономических системах при помощи таких методик, разрабатывалась как «теория управляемого хаоса» (3. Бжезинский, С. Курдюмов, В. Лепский, С. Манн, Г. Саймон, Дж. Шарп и другие). На примерах попыток создания новых систем управления наукой, в том числе - российской наукой, мы видим также не что иное, как проявление известного метода «проб и ошибок». (Предположение о применении приема «окон Овертона» не рассматриваем.)

Обращаясь вновь к модели HIDS, заметим, что порядок организационных форм структурирован целями. Организация проявляется на определенном уровне развития сообщества как обучающаяся, но она еще не зафиксировала цель, не произошел еще окончательный выбор.

В этом случае, а в ситуациях неопределенности это наиболее естественное решение администратора, организации предлагается некая институциональная форма (квазивербализованная посредством дискурса, как в рассмотренных выше примерах «семантических новаций»). В процессе деятельности вырабатывается цель (например, новое научное направление, разработка), формируются, возможно новые, способы мышления, а следом, при необходимости - новые организационные формы. Так, по принципу своеобразных «качелей», развивается научное предприятие: против часовой, затем уже - по часовой стрелке, когда механизм будет 
запущен, а инновационный цикл войдет в фазы опытного образца и коммерциализации.

Заметим вместо заключения: результаты итальянского кейсстади, полученные 10 лет назад, показали, что «неуверенная итальянская реструктуризация, также как и массификация академических исследований генерирует высокую академическую бюрократизацию и низкую эффективность исследовательских организаций» $[8$, с. 48]. Отсутствие долгосрочной национальной стратегии и последовательной политики в сфере научных исследований, вкупе с маркетизацией, привели к отрицательным последствиям во всей инновационной системе Италии. Автор отметила параллели в глобальных тенденциях и призвала правительства обратить внимание на возможные негативные последствия непродуманных стратегических изменений в национальных научных системах.

Обращаясь же к тезисам, вынесенным в эпиграф к данной статье, заметим, что новые категории научно-технической политики формируют не только научную сферу, но и новое общество.

\section{Список литературы}

1. Доклад ЮНЕСКО по науке: на пути к 2030 году = UNESCO Science Report: towards 2030 / UNESCO. -2015.

2. Дэвид П.А., Форэ Д. Экономические основы общества знания // Экономический вестник Ростовского государственного университета. - 2003. - Т. 1, № 1. C. $29-55$.

3. Егерев С.В. Наука толпы и наука граждан // Общественные науки и современность. - 2018. - № 3. - С. 153-162.

4. Макарин А.В. Власть бюрократии // Политическая социология: учебник / под ред. Ж.Т. Тощенко. - М.: Юрайт, 2012. - С. 190-211.

5. Пястолов С.М. Феномен образования в меняющемся обществе // Экономический вестник Ростовского государственного университета. - 2003. - Т. 1, № 1. - С. 56-76.

6. Пястолов С.М. Динамика институциональных форм на переднем крае науки // Journal of institutional studies. - 2018. - № 1. - C. 107-124.

7. Пястолов С.М. Развитие концепций и моделей измерения инноваций: материалы научно-практического семинара: сводный реферат // Социальные и гуманитарные науки. Отечественная литература. Сер. 8, Науковедение: реферативный журнал / Российская академия наук. Институт научной информации по общественным наукам. - М.: ИНИОН РАН, 2017. - № 3. - С. 97-106. 
8. Coccia M. Bureaucratization in public research institutions // Minerva. - L., 2009. Vol. 47, N 1. - P. 31-50.

9. Fagerberg J., Verspagen B. Innovation studies - The emerging structure of a new scientific field // Research Policy. - 2009. - N 38. - P. 218-233.

10. Flink T., Kaldewey D. The new production of legitimacy: STI policy discourses beyond the contract metaphor // Research Policy. - 2018. - N 47. - P. 14-22.

11. Genus A., Stirling A. Collingridge and the dilemma of control: Towards responsible and accountable innovation // Research Policy. - 2018. - N 47. - P. 61-69.

12. Giustiniano L., Cunha M., Stewart C. The dark side of organizational improvisation: Lessons from the sinking of Costa Concordia // Business Horizons. - 2016. N 59. - P. 223-232.

13. Hirschman A. Essays in trespassing: economics to politics and beyond. - Cambridge, $1981 .-320 \mathrm{p}$.

14. National Academies of Sciences, Engineering, and Medicine: Triennial Review of the National Nanotechnology Initiative. - Washington, DC: The National Academies Press, 2016. - 148 p.

15. National Academies of Sciences, Engineering, and Medicine. Fostering Integrity in Research. - Washington, DC: The National Academies Press, 2017. - 326 p.

16. National Academies of Sciences, Engineering, and Medicine. Open Source Software Policy Options for NASA Earth and Space Sciences. - Washington, DC: The National Academies Press, 2018. - 108 p.

17. Science - The Endless Frontier: A Report to the President on a Program for Postwar Scientific Research by V. Bush, National Science Foundation. - 1960. - Reprint. First published 1945.

18. The maturing of gamification research. Editorial // Computers in Human Behavior. 2017. - Vol. 71. - P. 450-454. 